This item was submitted to Loughborough's Research Repository by the author.

Items in Figshare are protected by copyright, with all rights reserved, unless otherwise indicated.

\title{
Condition monitoring of permanent magnet synchronous generator for wind turbine applications
}

\section{PLEASE CITE THE PUBLISHED VERSION}

http://systol16.cs2ac.upc.edu/

\section{PUBLISHER}

(C) Institute of Electrical and Electronics Engineers (IEEE)

VERSION

AM (Accepted Manuscript)

LICENCE

CC BY-NC-ND 4.0

\section{REPOSITORY RECORD}

Ibrahim, Raed Khalaf, and Simon J. Watson. 2019. "Condition Monitoring of Permanent Magnet Synchronous Generator for Wind Turbine Applications”. figshare. https://hdl.handle.net/2134/22953. 


\title{
Condition Monitoring of Permanent Magnet Synchronous Generator for wind turbine applications
}

\author{
Raed Khalaf Ibrahim ${ }^{1}$ and Simon Watson ${ }^{2}$
}

\begin{abstract}
Wind energy has gained a considerable attention from industries and academia to increase the reliability and availability of wind turbines (WTs) and, consequently, to reduce wind energy cost. With this attention has come investments and new technologies from WT manufacturers as industrial solutions. Among these technologies the new arrivals, the variable speed generation systems based on permanent magnet synchronous generators (PMSGs) with full-scale power converters are an emerging and promising technology. Better designs of the WT components is of course one answer to the solution of this problem; the other is condition monitoring of the WT systems. This allows to reduce maintenance cost, hardware damaging and unscheduled downtime. In this context, this paper investigates the possibility to detect mechanical faults by analysing the electrical signals with the aim of improving the reliability of WTs based on PMSGs. Rotor eccentricity is used as an illustrative example to describe how the fault signature frequencies may occur in PMSG current signals, and potentially how they may deviate from a healthy state, firstly under steady state, constant speed test operation and secondly under transient, variable speed conditions. Simulation results yield valuable information for condition monitoring and effective algorithm development for fault detection.
\end{abstract}

\section{INTRODUCTION}

Wind power has been one of the fastest growing power sources in the world over the last two decades, growing from a tiny $7.6 \mathrm{GW}$ in 1997 to $370 \mathrm{GW}$ in 2014 [1]. The worldwide wind capacity reached $392.927 \mathrm{GW}$ by the end of June 2015, out of which 21.6 GW were added in the first six months of 2015. This increase is substantially higher than in the first half of 2014 and 2013, when 17.6 GW respectively $13.9 \mathrm{GW}$ were added. All wind turbines (WTs) installed worldwide by mid-2015 can generate $4 \%$ of the worlds electricity demand [2]. As a large number of WTs are being installed and connected to power systems, it becomes more and more challenging for manufacturers to monitor and maintain all of these machines. In order to make wind energy a competitive energy source in the energy market, the matters of reliability and cost should be addressed. To reduce the cost of wind energy, there is a need to improve WT availability and to reduce the maintenance cost [3]. This need is even more important in the offshore environment due to the harsh environmental conditions and the significant additional cost incurred by catastrophic failure should offshore machines not be maintained in a timely

Raed Khalaf Ibrahim and Simon Watson are with the Department of Electronic and Electrical Engineering, Centre for Renewable Energy Systems Technology (CREST), Loughborough University, UK R.Ibrahimelboro.ac.uk, S.J.Watsonelboro.ac.uk fashion. For example, failure of a $\$ 1500$ bearing a WT could lead to a $\$ 100,000$ gearbox replacement, a $\$ 50,000$ generator rewind and another $\$ 70,000$ in expenses to replace the failed components [4].

The signature of electrical signals has been widely applied for diagnosis of both electrical and mechanical faults of electrical machines in conventional generation plants. There are several advantages that monitoring the electrical signals offers when compared to other condition monitoring methods. For example, electrical analysis can provide a reliable indication of the presence of a fault for the monitored system; it can indicate the location and severity of the fault; it can give immediate information about the state of health of that system [5], in contrast with oil analysis, where several days may elapse between the sample collection and its analysis. Moreover, the main driver for using electrical signals is to reduce costs given that the electrical current and voltage are continuously measured [6]. Thus, monitoring the electrical signals has gained more attention from researchers and industry for WT condition monitoring and fault diagnosis.

A number of generator configurations are used in the conversion of wind energy to maximize wind capture, reduce costs and improve reliability. The doubly fed induction generator has been used for many years for variable speed drives and still has the largest world market share [7]. An alternative generator configuration for a WT is the permanent magnet synchronous generator (PMSG). It has become more and more attractive in recent years as its costs have decreased and performance improved. As the use of a PMSG allows a WT to operate in variable-speed conditions under varying wind speeds, the current signals acquired from the generator terminals of the PMSG are always non-stationary, which means that the frequency of the signal is proportional to the wind speed so that the impact of the rotational speed on the fault frequencies needs to be considered if it is to be used for condition monitoring. A number of works discuss the reliability of PMSGs based WTs, but no detailed analysis, investigation, and explanation of the behavior has yet been published. Accordingly, the PMSG configuration is chosen to investigate the fault signatures with the aim of developing knowledge based fault detection method for performing online faults detection in variable speed WTs. In this paper, rotor eccentricity is chosen as case studies to investigate mechanical faults in a PMSG. 


\section{PERMANENT MAGNET SYNCHRONOUS GENERATOR}

Basically, a WT can be equipped with any type of threephase generator. From the 1970s until 1990s, most of the installed WTs were designed using a squirrel cage induction generator running close to fixed speed and directly connected to the grid [8]. Nowadays, most of the installed WTs are variable speed machines, based on doubly fed induction generators, sharing the market with wound rotor synchronous generators and the new arrivals, based on PMSGs. In this section, the essential properties of the PMSG are briefly described. For a detailed analysis of generator types, the reader is referred to the standard literature in this field [9].

PMSGs are favoured in WTs due to their light weight, high power density, and high efficiency [10]. The PMSG is often directly coupled with the turbine, eliminating the need for a gearbox and its associated cost and maintenance issues, whilst increasing the system reliability [10]. They are not only preferred in small scale WTs but also in large MW applications. The PMSG is much more expensive than an induction generator of a similar size. However, it has one clear advantage compared with other generators: namely, it does not need reactive magnetizing current. Figure1 shows a scheme using a PMSG where the magnetic field inside the generator is produced by permanent magnets on the rotor. Because there is no field winding in this generator, there is no associated $I^{2} R$ loss so that this type of generator has a very high efficiency, well above $90 \%$.

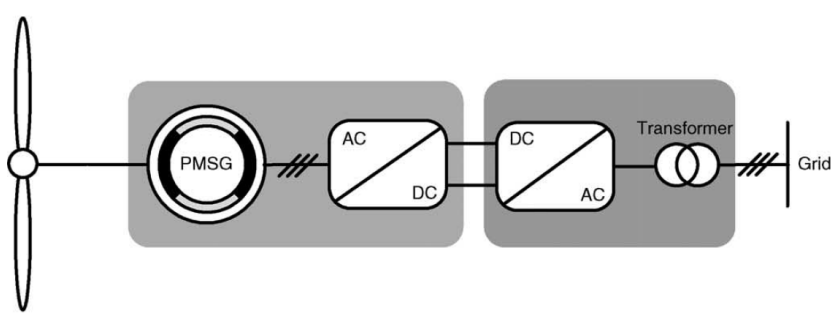

Fig. 1: Schematic diagram of a typical PMSG wind turbine [11]

In PMSGs, the frequency is a function of the rotational speed. Additionally, the rotor of the PMSG rotates at the same speed as the magnetic field produced by the stator windings; this synchronous speed $\omega_{s}$ (rev/min) can be expressed as:

$$
\omega_{s}=\frac{60 f}{p}
$$

where $f(\mathrm{~Hz})$ is the frequency of the stator currents and $p$ pairs of poles. In PMSGs, if the field in the stator windings is rotating at $1000 \mathrm{rpm}$, the rotor also rotates at $1000 \mathrm{rpm}$. As the use of a PMSG allows a WT to operate in variablespeed conditions under varying wind speeds, the current signals acquired from the generator terminals of the PMSG are always non-stationary, which means that the frequency of the signal is proportional to the wind speed so that the impact of the rotational speed on the fault frequencies needs to be considered if it is to be used for condition monitoring.

\section{FAULT SIGNATURE ANALYSIS IN WIND TURBINE CURRENT SIGNALS}

Motor current signature analysis (MCSA) has been studied extensively for fault detection in AC motors [12], [13]. These papers showed that mechanical faults such as unbalanced load and shaft misalignment essentially create a rotor eccentricity inside the motor. These types of faults introduce sideband harmonics around the fundamental frequency in the motor current spectrum. MCSA has the potential to be adopted by the wind power industry as a way of condition monitoring the drive train. A number of wind turbine faults may manifest themselves as some form of generator rotor eccentricity, including generator bearing faults, drive train misalignment, blade imbalance, pitching faults and possibly even gearbox faults. Similar to AC motors [14], [15], faults which lead to drive train and generator rotor eccentricity in WTs will generate harmonics at particular frequencies (called fault signatures) in the frequency spectra of generator current signals. Potentially, these fault signatures could be used to detect incipient failure if they can be clearly detected during the early stages of a developing fault. Thus, the diagnosis of rotor eccentricity in a PMSG is used as an illustrative example to describe how fault signature frequencies may occur during a mechanical fault in PMSG current signals, and potentially how they may deviate from a healthy state.

The diagnosis of rotor eccentricity in a PMSG has been studied in [16]. The authors reported that a rotor eccentricity of the PMSG can cause an air-gap asymmetry in the PMSG. This air-gap asymmetry will cause a torque variation of the PMSG, which will modulate the output current. Accordingly, the characteristic frequencies $f_{\text {eccent }}$ of the rotor eccentricity in the current signal of the PMSG based wind turbine can be expressed as follows:

$$
f_{\text {eccent }}=\left(1 \pm \frac{2 k-1}{p}\right) \cdot f
$$

Where $f_{\text {eccent }}$ and $f$ are the rotor fault and fundamental frequency components for a PMSG, respectively, $k$ is an integer $(k=1,2,3, \ldots)$ and $p$ is the number of pole pairs. As mentioned previously, the fundamental frequency in the PMSG is proportional to the rotational speed as explained in Equation (1) which clearly indicates that the current signals acquired from the generator terminals of the PMSG are always nonstationary, meaning the characteristic of the signal is varying with time. This will be briefly discussed in the results section.

\section{MODELLING AND SIMULATION}

To simulate the behavior of a PMSG under abnormal conditions, a WT is modelled in Simulink/MATLAB. The model consists of the following subsystems:

- Wind Speed Model; 
- Rotor Model;

- Pitch Control System;

- Drivetrain Model;

- Generator model;

Some components are not considered in this paper, including yaw systems, tower, bearings, brakes model and power converter. This is not considered as a problem, because the main topic of interest in this work is to extract mechanical fault signatures from the electrical signals, and the impact of those components on this study can be assumed to be rather limited. The subsystem models of WT are presented below.

\section{A. Wind Speed Model}

In simulation work it is often difficult to obtain appropriate measured data. In these circumstances it is convenient to be able to synthesis data with the required statistical properties. The simplest model to generate short-term wind speed variations with certain characteristics, such as speed range or turbulence intensity, which a WT will experience can be written as follows;

$$
U_{t+1}=r U_{t}+(1-r) \bar{U}+\varepsilon_{t}
$$

$U_{t+1}$ is the value of wind speed at time $t+1, U_{t}$ the value at $t, \bar{U}$ the desired mean value, $r$ the autocorrelation at unit lag and $\varepsilon_{t}$ a Gaussian noise term. An example of a wind speed sequence generated using this approach is shown in Figure 2.

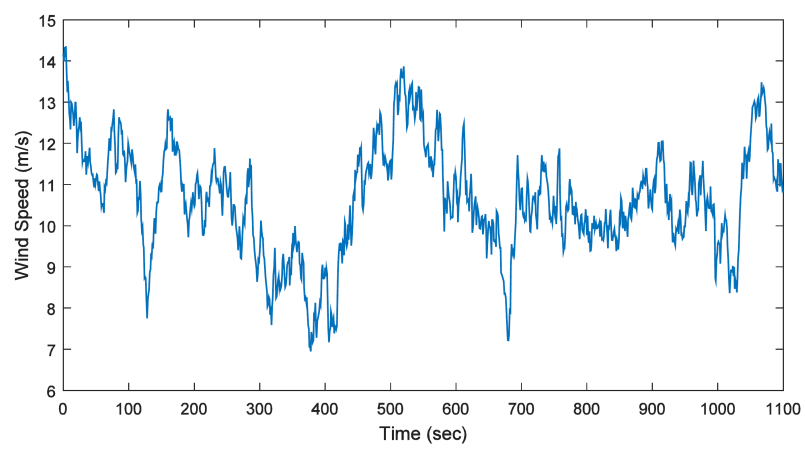

Fig. 2: Example of a simulated wind speed sequence

\section{B. Rotor Model}

The rotor transfers the kinetic energy from the wind into mechanical energy at the rotor shaft by aerodynamic forces producing lift on the blades. The kinetic energy of a cylinder of air of radius $R$ traveling with wind speed $v_{w}=U_{t+1}$ corresponds to a total wind power $P_{w}$ within the rotor swept area of WT. The WT mechanical power output can be defined as :

$$
P_{w}=\frac{1}{2} \rho \pi R^{2} v_{w}^{3} C_{P}(\lambda, \beta)
$$

where $P_{w}$ is the extracted wind power; $\rho$ is the air density $\left(1.225 \mathrm{~kg} / \mathrm{m}^{3}\right) ; R$ is the rotor radius; and $C_{P}$ is the efficiency coefficient of the turbine which is a function of the tip-speed ratio $\lambda$ and the blade pitch angle $\beta$. The tip-speed ratio $\lambda$ is expressed as :

$$
\lambda=\frac{\omega_{t} R}{v_{w}}
$$

where, $\omega_{t}$ is the turbine rotational speed. If the mechanical torque $T_{t}$ is to be applied instead of the mechanical power $P_{t}$, it can be easily calculated from the dynamic theory of rotating machines by using the turbine rotational speed $\omega_{t}$ :

$$
T_{t}=\frac{P_{t}}{\omega_{t}}
$$

\section{Pitch Control System}

The pitch control system is active only in high wind speeds. In these circumstances, the rotor speed can no longer be controlled by increasing the generated power, as this would lead to overloading the generator. Thus, the power efficiency coefficient is reduced in order to limit the the mechanical power extracted from the wind. This prevents the rotor speed from becoming too high, which would result in too high loads.

\section{Drivetrain Model}

The PMSG configuration may or may not have a gearbox, and they are connected to the grid through a full-scale converter. But, using a gearbox would increase the speed of the generator shaft, and as a result, reduce the size of generator. However, the equivalent model of a WT drive train is presented in Figure 3. The masses correspond to a large mass of the WT rotor, masses for the gearbox wheels and a mass for the generator respectively.

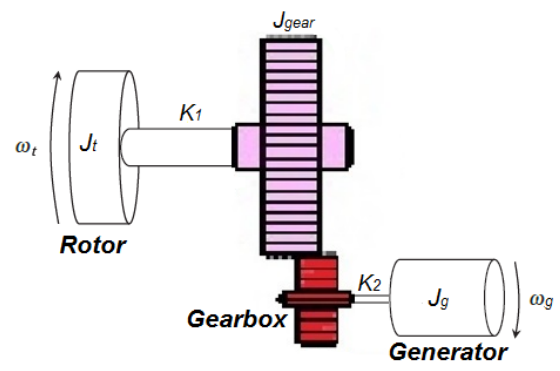

Fig. 3: Three masses model of the drive train.

However, the moment of inertia for the shafts and the gearbox wheels can be neglected because they are small compared with the moment of inertia of the WT or generator [17]. We therefore use a two-mass representation of the drive train by considering an equivalent system with an equivalent stiffness. The two-mass representation is described by the equations: 


$$
\begin{aligned}
J_{t} \frac{d^{2}}{d t^{2}} \theta_{t} & =-K\left(\theta_{t}-\theta_{g}\right), \\
J_{g} \frac{d^{2}}{d t^{2}} \theta_{g} & =-K\left(\theta_{g}-\theta_{t}\right) .
\end{aligned}
$$

$J_{t}, J_{g}$ are the moments of inertia of the turbine and generator respectively $\left(\mathrm{kgm}^{2}\right), \omega_{g}$ is the rotational speed of the generator $(\mathrm{rad} / \mathrm{s}), \theta_{t}, \theta_{g}$ are the rotational displacements of the turbine and generator respectively ( $\mathrm{rad}), \mathrm{K}$ is the shaft stiffness $(\mathrm{Nm} / \mathrm{rad})$.

\section{E. Generator model}

The detail description and model equation derivation of PMSG can be found in most power system and electric machine references. The PMSG model can be described using following equations in the $\mathrm{d}-\mathrm{q}$ rotor reference frame:

$$
\begin{gathered}
\frac{\partial}{\partial t} i_{d s}=\frac{1}{L_{d}} v_{d s}-\frac{R_{s}}{L_{d}} i_{d s}+\frac{L_{q}}{L_{d}} \omega_{r} i_{q s} \\
\frac{\partial}{\partial t} i_{q s}=\frac{1}{L_{q}} v_{q s}-\frac{R_{s}}{L_{q}} i_{q s}-\frac{L_{d}}{L_{q}} \omega_{r} i_{d s}-\frac{\omega_{r}}{L_{q}} \psi_{m} \\
T_{e}=1.5 n_{p}\left[\psi_{m} i_{q s}+\left(L_{d}-L_{q}\right) i_{d s} i_{q s}\right] \\
\frac{\partial}{\partial t} \omega_{r}=\frac{p}{J}\left(T_{e}-T_{t}\right) \\
\frac{\partial}{\partial t} \theta_{r}=\omega_{r}
\end{gathered}
$$

where $\mathrm{d}$ and $\mathrm{q}$ refer to the physical quantities that have been transformed into the d-q synchronous rotating reference frame, $i_{d s}$ and $i_{q s}$ are the stator currents on the $\mathrm{d}$ and $\mathrm{q}$ axis, respectively. $R_{s}$ is the stator resistance, $L$ is the stator inductance, $T_{e}$ is the electrical torque, $\psi_{m}$ is the permanent magnetic flux and $p$ is the pole pairs, $\omega_{r}, \theta_{r}$ and $J$ are the angular velocity of the rotor, the rotor angular and inertia of rotor, respectively. The model parameters used are detailed in Table 1.

TABLE I: Model Parameters.

\begin{tabular}{|l|l|}
\hline \multicolumn{2}{|c|}{ PMSG } \\
\hline Cut-In, Rated, Cut-Out Wind Speed & $3 \mathrm{~m} / \mathrm{s}, 12 \mathrm{~m} / \mathrm{s}, 25 \mathrm{~m} / \mathrm{s}$ \\
\hline Rated Tip Speed & $80 \mathrm{~m} / \mathrm{s}$ \\
\hline Rotor Diameter & $90 \mathrm{~m}$ \\
\hline Gearbox Ratio & $1: 77.4$ \\
\hline Line-Line Voltage (RMS) & $690 \mathrm{v}$ \\
\hline Frequency & $50 \mathrm{~Hz}$ \\
\hline Pole Pairs & 3 \\
\hline Rated Generator Speed (RPM) & 1000 \\
\hline
\end{tabular}

\section{RESULTS AT CONSTANT SPEED}

Simulation results for a PMSG model under healthy condition and rotor eccentricity are discussed in this section. A series of tests were carried out using this model. The model was run at three operational points of constant wind speeds under both healthy and faulty rotor conditions. The first test was run at low, at the nominal and high wind speed to allow the model to operate at constant sub-synchronous, synchronous and super-synchronous speeds respectively. For each simulation result, data were recorded for 10 seconds at $5 \mathrm{kHz}$ sampling frequency and analysed using the fast fourier transform (FFT) algorithm in MATLAB. Figure 4 shows the stator current spectra for the healthy generator operating at different wind speed operation. The spectra respond as expected from Equation (1) and are consistent across the simulation results. Small variations in the simulated frequencies compared to the calculated values a result of minor differences when the wind speed converted to the rotational speeds. At the super-synchronous speed shown in Figure 4, the fundamental frequency remains at $49.97 \mathrm{~Hz}$ due to the pitch control is used to keep the rotational speed at the synchronous value which is 1000 RPM in this model, and there is also a slight increase in the harmonic content of the signal. This is mainly due to the fluctuation in the rotational speed while the control is pitching.

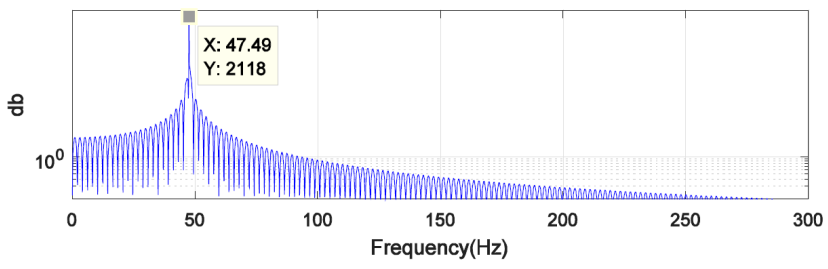

(a)

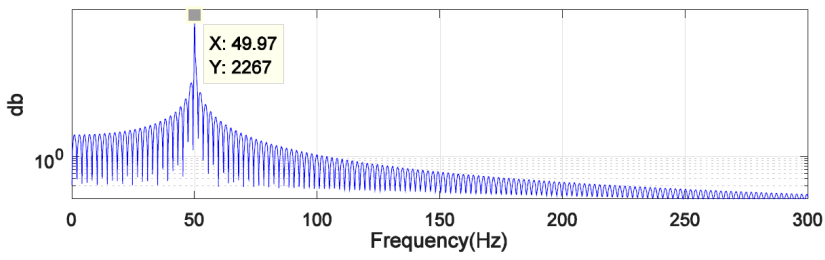

(b)

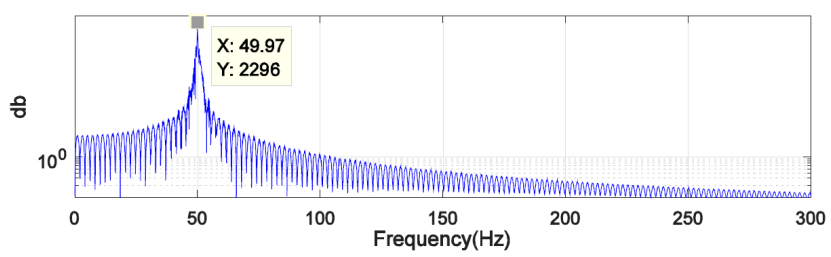

(c)

Fig. 4: Stator current spectra for the healthy PMSG at (a) low, (b) nominal and (c) high wind speed.

Figures 5 shows the stator current spectra after rotor eccentricity conditions were applied. The fault signature 
frequencies are clearly shown around the fundamental frequency and these frequencies are consistent for each case. The fault signature frequencies are labelled for each case. Using Equation (2) we can calculate these frequencies by setting $k=1$. Values for these frequencies are given in Table 2. A comparison of the simulated and calculated results showed agreement. One can observe small variations in the simulated frequencies compared to the calculated values a result of firstly, minor differences when the wind speed converted to the rotational speeds and secondly, the presence of the pitch control which is active only in high wind speeds above $12 \mathrm{~m} / \mathrm{s}$ in order to limit the the mechanical power extracted from the wind, consequently, this prevents the rotational speed from becoming above the synchronous value which is 1000 RPM in this model.

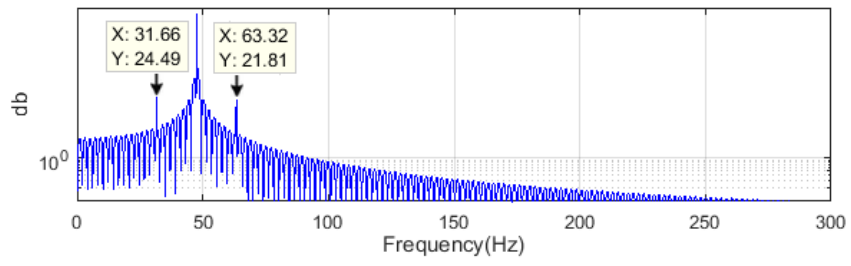

(a)

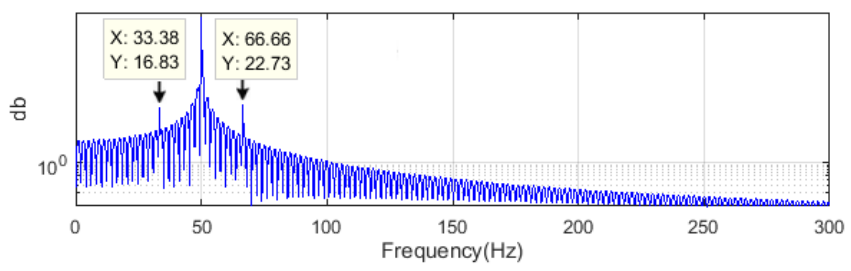

(b)

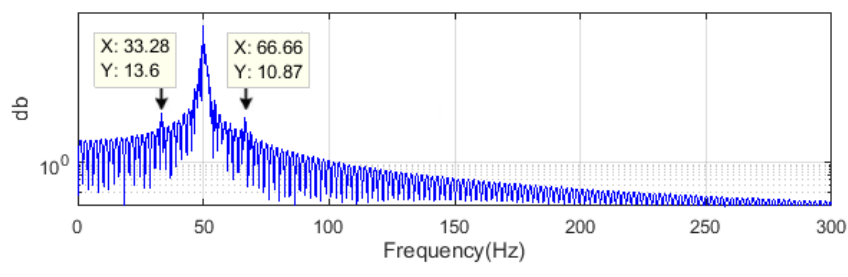

(c)

Fig. 5: Stator current spectra for the faulty PMSG at (a) low, (b) nominal and (c) high wind speed.

TABLE II: Comparison of calculated and simulated results.

\begin{tabular}{|c|c|c|c|c|}
\hline Generator Speed & \multicolumn{2}{|c|}{ Calculated Results } & \multicolumn{2}{c|}{ Simulated Results } \\
\cline { 2 - 5 }$\omega_{s}(\mathrm{RPM})$ & $f(\mathrm{~Hz})$ & $f_{\text {eccent }}(\mathrm{Hz})$ & $f(\mathrm{~Hz})$ & $f_{\text {eccent }}(\mathrm{Hz})$ \\
\hline 950 & 47.5 & $(31.66,63.33)$ & 47.49 & $(31.66,63.32)$ \\
\hline 1000 & 50 & $(33.33,66.66)$ & 49.97 & $(33.38,66.66)$ \\
\hline 1050 & 52.5 & $(34.99,69.99)$ & 49.97 & $(33.38,66.66)$ \\
\hline
\end{tabular}

\section{RESULTS AT VARIABLE SPEED}

Generally PMSGs operate at variable speed, therefore the model was run at variable speed to investigate the potential for fault frequency tracking. The driving conditions were based on the variable speed as shown in Figure 2. Although Figure 6 shows the stator current spectra for the healthy PMSG at variable speed, it seems to be for a faulty machine, because the rotational speed in PMSG is proportional to the wind speed so that the number of harmonics in the PMSG spectrum will increase with the rotational speed, as described by Equation (1).

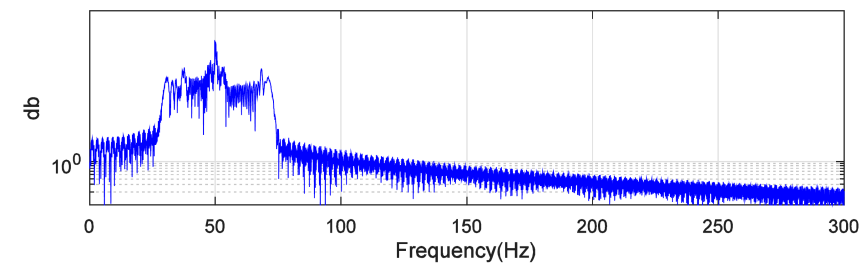

Fig. 6: Stator current spectra for the healthy PMSG at variable speed.

Applying the fault we find in Figure 7 it is difficult to distinguish between the stator current spectra during healthy and faulty conditions, and, consequently, it is difficult to extract the fault features from the spectrum of the original non-stationary current signal directly because the fault signature frequencies are buried in wide-band dominant frequency components (i.e. harmonics due to variable rotational speeds) of the current signal that are irrelevant to the fault.

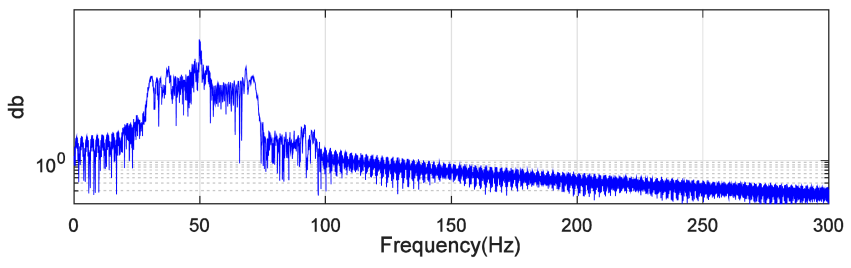

Fig. 7: Stator current spectra for the faulty PMSG at variable speed.

In order to have an idea of how the additional harmonics would influence the previous simulation, the same datasets are used again in the next example (Figure 8), this time after increasing the fault levels of rotor eccentricity of $50 \%$ and $75 \%$, respectively, given as a percentage of the fault amplitude. What is shown here is that the fault signature frequencies, that were labelled and identified as a function to the fundamental frequency as explained in Equation (2). The existence of the additional harmonics in the current spectrum has generated a wide-band dominant frequency components. So it is clear from this simulation, that at variable wind speed will result in a signal that contains a non-stationary noise will lead to again a wide-band non-stationary frequency components. 


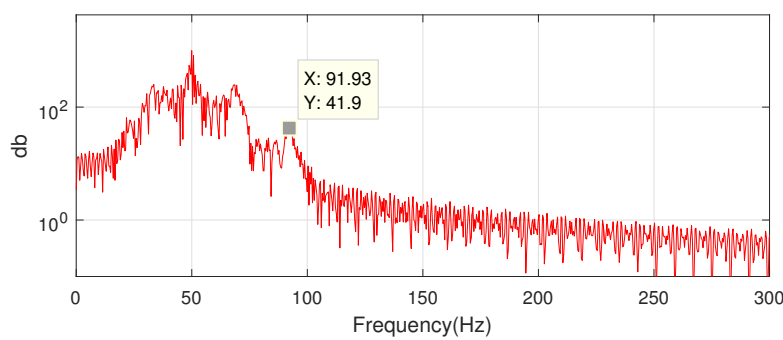

(a)

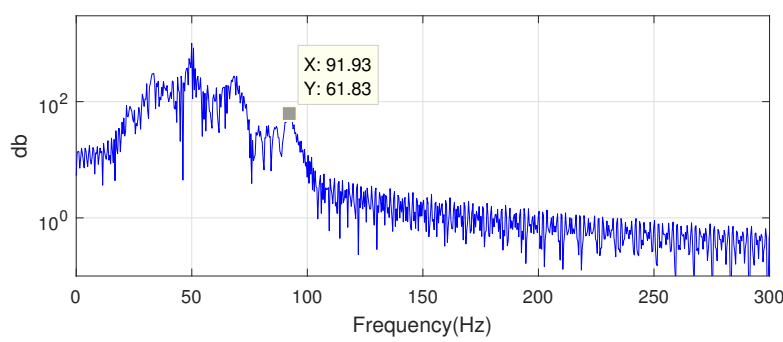

(b)

Fig. 8: Stator current spectra for the fault levels of rotor eccentricity of (a) $50 \%$ and (b) $75 \%$.

\section{CONCLUSION}

This paper has studied the diagnosis of rotor eccentricity in a PMSG as an illustrative example to describe how fault signature frequencies may occur during a mechanical fault in PMSG current signals, and potentially how they may deviate from a healthy state. A wind turbine model base on PMSG was implemented in the MATLAB/Simulink environment. The spectrum of stator current was calculated using FFT. Based on this study, the main conclusions are as follows:

- Healthy and faulty PMSG has clearly defined and calculable frequencies in current signals which can be predicted using the analytical expressions given;

- Mechanical faults have a particular signature that should be detectable in current signals at constant speeds;

- Detecting mechanical faults by current measurements at variable speed potentially depends on the severity of the fault;

- For variable speed conditions the current signal has non-stationary characteristic, and thus very difficult to extract fault signature without a dedicated signal processing;

Further work will include deeper investigation of mechanical fault frequencies and their detection from non-stationary current signals by using advanced signal processing.

\section{REFERENCES}

[1] Global Wind Energy Counci, Global Cumulative Installed Capacity 1997-2014, [Online]: http://www.gwec.net/global-figures/graphs/, 2014.

[2] The World Wind Energy Association, WWEA BULLETIN SPECIAL ISSUE 2015, [Online]: http://www.wwindea.org/wwea-bulletinspecial-issue-2015/.
[3] S. J. Watson, B. J. Xiang, W. Yang, P. J. Tavner, and C. J. Crabtree, "Condition monitoring of the power output of wind turbine generators using wavelets," Energy Conversion, IEEE Transactions on, vol. 25, no. 3, pp. 715-721, 2010.

[4] R. Hyers, J. McGowan, K. Sullivan, J. Manwell, and B. Syrett, "Condition monitoring and prognosis of utility scale wind turbines," Energy Materials, vol. 1, no. 3, pp. 187-203, 2006.

[5] P. Zhang and P. Neti, "Detection of gearbox bearing defects using electrical signature analysis for Doubly-fed wind generators," 2013 IEEE Energy Conversion Congress and Exposition, pp. 4438-4444, Sept. 2013.

[6] J. P. Barton and S. J. Watson, "Analysis of electrical power data for condition monitoring of a small wind turbine," IET Renewable Power Generation, vol. 7, no. 4, pp. 341-349, 2013.

[7] Y. Zhou, P. Bauer, J. A. Ferreira, and J. Pierik, "Operation of gridconnected dfig under unbalanced grid voltage condition," Energy Conversion, IEEE Transactions on, vol. 24, no. 1, pp. 240-246, 2009.

[8] H. Li and Z. Chen, "Overview of different wind generator systems and their comparisons," Renewable Power Generation, IET, vol. 2, pp. 123-138, June 2008.

[9] J. Machowski, J. Bialek, and J. Bumby, Power system dynamics: stability and control. John Wiley \& Sons, 2011.

[10] X. Yang, D. Patterson, and J. Hudgins, "Permanent magnet generator design and control for large wind turbines," in Power Electronics and Machines in Wind Applications (PEMWA), 2012 IEEE, pp. 1-5, IEEE, 2012.

[11] F. Blaabjerg, R. Teodorescu, M. Liserre, and A. V. Timbus, "Overview of control and grid synchronization for distributed power generation systems," Industrial Electronics, IEEE Transactions on, vol. 53, no. 5, pp. 1398-1409, 2006.

[12] S. Nandi and H. Toliyat, "Condition monitoring and fault diagnosis of electrical machines-a review," in Industry Applications Conference, 1999. Thirty-Fourth IAS Annual Meeting. Conference Record of the 1999 IEEE, vol. 1, pp. 197-204 vol.1, 1999.

[13] S. Nandi, H. Toliyat, and X. Li, "Condition monitoring and fault diagnosis of electrical motors-a review," Energy Conversion, IEEE Transactions on, vol. 20, pp. 719-729, Dec 2005.

[14] B. M. Ebrahimi, M. Javan Roshtkhari, J. Faiz, and S. V. Khatami, "Advanced eccentricity fault recognition in permanent magnet synchronous motors using stator current signature analysis," Industrial Electronics, IEEE Transactions on, vol. 61, no. 4, pp. 2041-2052, 2014.

[15] C. Crabtree, S. Djurovic, P. Tavner, and A. Smith, "Condition monitoring of a wind turbine dfig by current or power analysis," in Power Electronics, Machines and Drives (PEMD 2010), 5th IET International Conference on, pp. 1-6, April 2010.

[16] X. Gong and W. Qiao, "Current-based mechanical fault detection for direct-drive wind turbines via synchronous sampling and impulse detection," Industrial Electronics, IEEE Transactions on, vol. 62, no. 3, pp. 1693-1702, 2015.

[17] R. K. Ibrahim and S. Watson, "Effect of power converter on condition monitoring and fault detection for wind turbine," in Power Electronics, Machines and Drives, 2016. PEMD 2016. 8th IET Conference on, IET, 2016. 